ной и экологической безопасности Челябинской области, Ин-т экологии растений и животных УрО РАН; отв. ред. Н.С. Корытин. Екатеринбург: Изд-во Урал. ун-та, 2005. $450 \mathrm{c.}$

28. Зелёная книга Поволжья: Охраняемые природные территории Самарской области. Самара: Кн. издво, 1995. С. 150-200.

29. Саксонов С.В. Самаролукский флористический феномен. М.: Наука, 2006. 120 с.

30. Саксонов С.В. О видах растений, лишайников и грибов Красной книги Российской Федерации // Самарская Лука: Бюллетень. 2006. № 17. С. 253-285.

31. Ужамецкая Е.А. Васильково-качимовая ассоциация // Зелёная книга Самарской области: редкие и охраняемые растительные сообщества. Самара: СамНЦ РАН, 2006. С. 133-134.

32. Флора памятника природы «Гора Зелёная» Елховского района Самарской области / С.В. Саксонов, А.В. Лобанова, А.И. Иванова, В.Н. Ильина и др. //
Вестник Волжского университета им. В.Н. Татищева. Серия «Экология». 2005. Вып. 5. С. 6, 20.

33. Флористическое разнообразие особо ценного Красносамарского лесного массива Самарской области: I. Сосудистые растения // Самарская Лука: проблемы региональной и глобальной экологии. Тольятти: Кассандра, 2010. Т. 19. № 1. С. 112-113, 127.

34. Матвеев Н.М., Филиппова К.Н., Дёмина О.Е. Систематический и экоморфный анализ флоры Красносамарского лесного массива в зоне настоящих степей // Вопросы экологии и охраны природы в лесостепной и степной зонах: Межвед. сб. науч. тр. Самара: Самарский университет. 1995. С. 41-71.

35. Оценка состояния флористического фиторазнообразия особо ценного Красносамарского лесного массива в целях научного обоснования проведения мероприятий по его охране и рациональному использованию (Отчет о НИР). Самара: 2008, 214 с.

\title{
THE ASSESSMENT OF BIO-ECOLOGICAL FEATURES OF PLANTS TULIPA BIEBERSTEINIANA SCHULT. ET SCHULT. FIL. IN THE MODEL FOREST HABITATS OF THE KRASNOSAMARSKY FOREST
}

(C) 2016

\section{M.G. Kotelnikova, postgraduate student of the Chair of Ecology, Botany and Nature Protection} Samara National Research University, Samara (Russia)

Abstract. The paper presents some preliminary results of the monitoring of Tulipa biebersteiniana Schult. et Schult. fil. plants (category of rare and endangered plant species). By summarizing the available sources of science literature we have compiled a general description of morphological and bio-ecological species characteristics. The results of the field study fulfilled in 2012-2015 in two population groups of the Krasnosamarsky forestry (Samara region) were used to determine morphometric parameters of Tulipa biebersteiniana plants. The data also helped us to assess the variability level and to make a comparison with plant quantitative traits given in the literature. It was found that the shoot length of Tulipa biebersteiniana plants varied in the range of $23 \ldots 50 \mathrm{~cm}$, the maximum average length of $40 \mathrm{~cm}$ are presented in plants of population group number two. The distribution of shoot length among individuals of the second population group is more stable, changes depending on the year of vegetation are poorly expressed. The lengths of shoots inside the range specified for the various parts of the area in the literature with a significant proportion of «high» plants in the population is studied. This may be a sign of good growth conditions for Fritillaria rutheni$c a$ that gives an opportunity to the plant conservation in natural communities in the absence of limiting anthropogenic factors.

Keywords: Tulipa biebersteiniana Schult. et Schult. fil.; morphological and bioecological features; quantitative and qualitative characteristics; shoot length; Krasnosamarsky forest; model biotope; Samara Region.

УДК 631.417 .2

\section{АГРОГЕННАЯ ТРАНСФОРМАЦИЯ ОРГАНИЧЕСКОГО ВЕЩЕСТВА ЧЕРНОЗЁМОВ КАЗАХСТАНА}

(C) 2016

А.К. Куришбаев, доктор сельскохозяйственных наук, профессор, председатель правления

Г.А. Звягин, докторант кафедры почвоведения и агрохимии

Казахский агротехнический университет им. С. Сейфуллина, Астана (Казахстан)

Н.В. Ярославцева, кандидат сельскохозяйственных наук,

научный сотрудник отдела биологии и биохимии почв

Б.М. Когут, доктор сельскохозяйственных наук, заведующий отделом биологии и биохимии почв

Почвенный институт им. В.В. Докучаева, Москва (Россия)

Аннотация. В настоящее время, несмотря на широкую изученность временной динамики органического вещества пахотных почв в глобальном масштабе, значительный научный интерес представляет установление закономерностей его количественной трансформации на региональном уровне в зависимости от систем сельскохозяйственного использования с целью уточнения общемировых оценок запасов гумуса в связи с проблемой «парникового эффекта». В связи с этим была исследована современная динамика (1990-2015 гг.) органического вещества черноземов обыкновенных и южных в условиях длительных стационарных полевых опытов основного зерносеющего региона Северного Казахстана. На основании разновременных данных по содержа- 
нию Сорг и $\mathrm{N}$ в верхнем (в основном 0-25 см) слое целинных и старопахотных черноземов Акмолинской и Костанайской областей Казахстана выявлены особенности изменения содержания почвенного органического вещества. Показано, что содержание гумуса в черноземе обыкновенном значительно выше, чем таковое в черноземе южном карбонатном. Дана оценка трансформируемого и инертного пулов органического углерода в целинном и пахотных вариантах чернозема южного. Установлено, что в настоящее время в результате воздействия различных способов обработки черноземов южных замедляются темпы снижения содержания гумуса по сравнению с таковыми предшествующего периода их сельскохозяйственного использования, но практически они, в т.ч. и плоскорезные обработки, не приостанавливают процесс дегумусирования. Содержание гумуса в почвах на вариантах с бессменной яровой пшеницей уже близко таковому на бессменном чистом пару. Имеются достаточные основания предполагать, что причиной дегумусирования черноземов южных могут выступать как биохимические (минерализация), так и физические (дефляция) потери гумуса. Особую опасность представляет ветровая эрозия, в результате которой гумус может снижаться ниже минимального его содержания, т.е. за счет убыли трудновосполнимой инертной части. На пахотных черноземах обыкновенных в последний период их сельскохозяйственного использования предположительно потерь гумуса не наблюдается, что вероятней всего связано с наличием защитных противоэрозионных лесополос на изучаемых полевых участках.

Ключевые слова: органическое вещество; чернозем обыкновенный; чернозем южный; агрогенные почвы; слабогумусированные почвы; зернопаровой севооборот; бессменная пшеница; плоскорезная обработка; нулевая технология; дегумусирование; инертный гумус; Северный Казахстан; Акмолинская область; Костанайская область.

Широко известна классификация черноземов В.В. Докучаева по содержанию гумуса в верхнем горизонте и карта изогумусовых полос. Общие закономерности снижения содержания и запасов гумуса при распашке целинных черноземов России были описаны ранее в фундаментальных трудах И.В. Тюрина [1] и М.М. Кононовой [2; 3]. По Казахстану тоже имеется подобная информация. Так, анализ данных литературы и экспериментальных результатов по изменению содержания гумуса в черноземах Северного Казахстана показал, что после распашки целинных почв и при дальнейшем использовании их под посевы зерновых культур без внесения достаточного количества органических и минеральных удобрений утрачено 25-30\% от его исходного содержания [4]. Представляет научный интерес оценка современной направленности динамики органического вещества за последние 25 лет трансформации пахотных черноземов Северного Казахстана.

Объектом исследования выбраны тяжелосуглинистые разновидности черноземов южных карбонатных среднемощных и черноземов обыкновенных среднемощных, сформированные на покровных карбонатных легких глинах, в условиях целины и длительных полевых опытов, заложенных на пашне, используемой более 60 лет.

Профиль исследуемых почв представлен горизонтами А (0-20 для целинного участка), $\mathrm{A}_{\text {пах }}$ (в среднем 0-25 см для пахотных участков), $\mathrm{B}_{1}(25-45 \mathrm{~cm}), \mathrm{B}_{2}$ (45-65 см), ВС (72-100 см), С (100-120 см). Отличительной особенностью южных черноземов является наличие карбонатов в верхнем слое (фиксируется вскипанием почвы от 5\% раствора соляной кислоты с поверхности), в то время как в обыкновенных черноземах они проявляются на глубине 40-50 cм.

Первый длительный полевой опыт Казахского научно-исследовательского института зернового хозяйства им. Бараева (КазНИИЗХ) был заложен в 1990 году на полях с. Дамса Шортандинского района Акмолинской области, а второй Карабалыкской опытной станции - в 2000 году в с. Белоглинское Карабалыкского района Костанайской области. Территория опытных пахотных участков находится в непосредственной близости от целинных в условиях слабоволнистой равнины.
В первом опыте исследования проводились в пятипольном зернопаровом севообороте (пар, пшеница, пшеница, пшеница, пшеница) и на вариантах бессменной пшеницы и бессменного чистого пара, а во втором опыте - в таком же севообороте, как и в первом опыте, в плодосменном севообороте (пар, пшеница, пшеница, горох, пшеница) и на вариантах бессменной пшеницы.

В опытах изучали влияние способов обработки почв (глубокая безотвальная, минимальная безотвальная, нулевая технология) и минеральных удобрений (табл. 1). В период отбора образцов опытные делянки находились под яровой пшеницей. Глубокая безотвальная обработка проводилась на глубину 2527 см плугом-глубокорыхлителем (ПГ-3,5), минимальная безотвальная обработка на глубину $12-14 \mathrm{~cm}$ - культиватором плоскорезным широкозахватным (КПШ-9). Во всех вариантах посев выполняли сеялкой зерновой стерневой (С $3 \mathrm{C}-2,1)$, а в варианте при нулевой обработке почв - сеялкой СЗС-2,1 с чизельными сошниками. Химическая обработка против сорняков проводилась на вариантах с минимальной обработкой и нулевой технологией за 5-6 дней до посева глифосфатом (36\%) в дозе 1,5-2,0 л/га.

Закладка и проведение опытов, отбор почвенных образцов, анализы и наблюдения проводили согласно общепринятым методикам [5; 6].

Анализ данных табл. 1-3 показал, что содержание гумуса в черноземе обыкновенном значительно выше, чем таковое в черноземе южном карбонатном. Причем эти различия проявляются как в целинных, так и в пахотных $(\mathrm{P}=0,95)$ вариантах почв. Данное положение вполне соответствует общим закономерностям гумусонакопления в зональном ряду почв Евразии [7]. Обогащенность гумуса черноземов обыкновенных азотом $(\mathrm{C} / \mathrm{N})$ согласно классификации Л.А. Гришиной, Д.С. Орлова [8] - высокая, в то время как таковая южных черноземов в основном - низкая.

При сельскохозяйственном использовании обоих подтипов черноземов в верхнем горизонте отмечается снижение содержания гумуса по отношению к таковому целинных аналогов. Однако если в черноземе южном потери органического вещества достигают 40 отн. \%, то в черноземе обыкновенном - 30 отн. \%. Сопоставляя эти данные с результатами исследо- 

ваний Н.В. Ярославцевой [4, с. 96-98] можно сделать следующий вывод. В южных черноземах падение содержания гумуса на современном этапе их агрогенной трансформации (за последние 25 лет) продолжа-

ется а в обыкновенных этот процесс практически приостановлен. Внесение минеральных удобрений (табл. 2, 3) несколько сдерживает процесс дегумусирования черноземов южных.

Таблица 1 - Содержание С и $\mathrm{N}$ в целинных и пахотных черноземах Казахстана

\begin{tabular}{|c|c|c|c|c|c|c|}
\hline \multirow{2}{*}{$\begin{array}{l}\text { № ва- } \\
\text { рианта }\end{array}$} & \multirow{2}{*}{ Варианты опыта } & \multirow{2}{*}{$\begin{array}{l}\text { Глубина } \\
\text { отбора, см }\end{array}$} & Гумус & Сорг & $\mathrm{N}$ & \multirow{2}{*}{$\mathrm{C} / \mathrm{N}$} \\
\hline & & & \multicolumn{3}{|c|}{ \% от массы почвы } & \\
\hline \multicolumn{7}{|c|}{$\begin{array}{c}\text { Чернозем южный карбонатный, длительность полевого опыта - } 25 \text { лет, } \\
\text { Акмолинская область, КазНИИ зернового хозяйства им. Бараева }\end{array}$} \\
\hline 1 & Целина & $0-20$ & 4,64 & 2,69 & 0,195 & 13,8 \\
\hline 2 & $\begin{array}{l}\text { Зернопаровой севооборот, IV КПП***, без удобрений, } \\
\text { обработка ПГ-3,5 на глубину 25-27 см }\end{array}$ & $0-26$ & 2,77 & 1,61 & 0,150 & 10,7 \\
\hline 3 & То же, без удобрений, без обработки & $0-26$ & 2,85 & 1,65 & 0,155 & 10,7 \\
\hline 4 & $\begin{array}{l}\text { То же, без удобрений, обработка КПШ-9 на глубину 12- } \\
14 \text { см }\end{array}$ & $0-26$ & 2,85 & 1,65 & 0,145 & 11,4 \\
\hline 5 & То же, без удобрений, нулевая технология & $0-26$ & 2,83 & 1,64 & 0,165 & 9,9 \\
\hline 6 & $\begin{array}{l}\text { То же, I КПП*, N30P20, плоскорезная обработка } \\
\text { на глубину 25-27 см }\end{array}$ & $0-25$ & 3,07 & 1,78 & 0,195 & 9,1 \\
\hline 7 & $\begin{array}{l}\text { То же, II КПП**, N30P20, плоскорезная обработка } \\
\text { на глубину 25-27 см }\end{array}$ & $0-25$ & 2,99 & 1,73 & 0,155 & 11,2 \\
\hline 8 & $\begin{array}{l}\text { Бессменная яровая пшеница, без удобрений, } \\
\text { без обработки, без гербицидов }\end{array}$ & $0-25$ & 2,71 & 1,57 & 0,150 & 10,5 \\
\hline 9 & $\begin{array}{l}\text { Бессменная яровая пшеница, N30P20, плоскорезная } \\
\text { обработка на глубину 25-27 см }\end{array}$ & $0-26$ & 2,72 & 1,58 & 0,185 & 8,5 \\
\hline 10 & Бессменный чистый пар, без удобрений, без гербицидов & $0-25$ & 2,60 & 1,51 & 0,125 & 12,1 \\
\hline \multicolumn{7}{|c|}{$\begin{array}{c}\text { Чернозем обыкновенный, длительность полевого опыта - } 15 \text { лет, } \\
\text { Костанайская область, Карабалыкская опытная станция }\end{array}$} \\
\hline 11 & Целина & $0-20$ & 5,74 & 3,33 & 0,420 & 7,9 \\
\hline 12 & $\begin{array}{l}\text { Бессменная яровая пшеница, N30P20, плоскорезная } \\
\text { обработка на глубину 25-27 см }\end{array}$ & $0-25$ & 4,42 & 2,56 & 0,335 & 7,6 \\
\hline 13 & То же, N30, плоскорезная обработка на глубину 25-27 см & $0-27$ & 4,03 & 2,34 & 0,305 & 7,7 \\
\hline 14 & $\begin{array}{l}\text { Плодосменный севооборот, IV КПП***, N30, нулевая } \\
\text { технология }\end{array}$ & $0-25$ & 3,99 & 2,31 & 0,305 & 7,6 \\
\hline 15 & То же, N30P20, нулевая технология & $0-25$ & 4,40 & 2,55 & 0,345 & 7,4 \\
\hline 16 & $\begin{array}{l}\text { Зернопаровой севооборот, I КПП*, без удобрений, } \\
\text { обработка на глубину 25-27 см }\end{array}$ & $0-27$ & 3,80 & 2,20 & 0,265 & 8,3 \\
\hline
\end{tabular}

Примечание. I КПП* - первая культура после пара, II КПП** - вторая культура после пара, IV KПП*** четвертая культура после пара.

Как известно, максимальные потери гумуса достигаются при длительном бессменном чистом паровании почв, что также зафиксировано нами и в 25летнем полевом опыте КазНИИ зернового хозяйства им. Бараева. Согласно М. Кёршенсу [9] в таких условиях устанавливается уровень минимального содержания гумуса. Располагая значением минимального содержания гумуса и величинами межлабораторных допустимых расхождений этого параметра можно построить шкалу гумусированности чернозема южного карбонатного Казахстана: меньше минимального содержания гумуса - <2,0-2,6, слабогумусированные $2,6-3,5$ среднегумусированные - 3,5-4,6, сильногумусированные - $>4,6$, аналогичную предложенной Б.М. Когутом [10] для пахотных почв России.

Следует отметить, что пахотные южные черноземы в соответствии с данными этой статьи, полученными в 2015 году, попадают в градацию «слабогумусированные», в то время как обобщенные результаты исследований Н.П. Масютенко с соавт. [11] и Б.М. Когута с соавт. [12] свидетельствуют о более высокой гумусированности этих почв на тот период исследований, и относятся к классу «среднегумусированных». Последний вывод вполне согласуется с отме- ченным выше выводом о продолжающемся снижении содержания гумуса в пахотных черноземах южных в последние 20-25 лет.

В соответствии с М. Кёршенсом [9] валовый органический углерод почвы состоит из инертного, практически не участвующего в процессах превращения, и трансформируемого органического углерода. Инертная фракция в основном зависит от условий местообитания и гранулометрического состава почв, а разлагаемая фракция, которая легко трансформируется в почвах, от условий хозяйствования. Содержание инертного гумуса близко понятию минимального, которое можно определить в условиях длительного (>20 лет) бессменного чистого парования почвы.

На рис. 1 видно, что содержание инертного углерода на черноземе южном карбонатном Северного Казахстана составляет 1,5\% от массы почвы. Максимальное содержание трансформируемого органического углерода (1,2\% от массы почвы) фиксируется на целинном участке, где в почву поступает наибольшее количество свежего органического вещества. На пахотных вариантах чернозема южного содержание трансформируемого органического углерода зна- 
Куришбаев А.К., Звягин Г.А., Ярославцева Н.В., Когут Б.М. Агрогенная трансформация органического вещества чернозёмов..

чительно ниже, чем на целине, и колеблется в интервале от 0,06 до 0,27\% (от массы почвы), при этом минимальные значения отмечаются на вариантах «бессменной яровой пшеницы».

Таблица 2 - Статистические характеристики по содержанию гумуса, органического углерода и азота в черноземах южных и обыкновенных при различных системах их сельскохозяйственного использования

\begin{tabular}{|c|c|c|c|c|}
\hline $\begin{array}{c}\text { Вариант } \\
\text { опыта }\end{array}$ & $\begin{array}{c}\text { М (\% от массы } \\
\text { почвы) }\end{array}$ & $\mathrm{S}$ & $\mathrm{m}$ & $\mathrm{V}, \%$ \\
\hline \multicolumn{4}{|c|}{ Чернозем южный карбонатный пахотный: } \\
\hline гумус & 2,85 & 0,13 & 0,04 & 4,4 \\
Сорг & 1,65 & 0,07 & 0,03 & 4,4 \\
$\mathrm{~N}$ & 0,16 & 0,02 & 0,01 & 11,2 \\
\hline Зернопаровой севооборот, без удобрений: \\
\hline гумус & 2,83 & 0,04 & 0,02 & 1,3 \\
Сорг & 1,64 & 0,02 & 0,01 & 1,2 \\
$\mathrm{~N}$ & 0,15 & 0,01 & 0,00 & 5,6 \\
\hline \multicolumn{5}{|c|}{ Зернопаровой севооборот, } \\
\hline с внесением удобрений (N30Р20): \\
\hline гумус & 3,03 & 0,06 & 0,04 & 1,9 \\
Сорг & 1,76 & 0,04 & 0,03 & 2,0 \\
$\mathrm{~N}$ & 0,18 & 0,03 & 0,02 & 16,2 \\
\hline \multicolumn{5}{|c|}{ Бессменная яровая пшеница: } \\
\hline гумус & 2,72 & 0,01 & 0,01 & 0,3 \\
Сорг & 1,58 & 0,01 & 0,01 & 0,4 \\
$\mathrm{~N}$ & 0,17 & 0,02 & 0,02 & 14,8 \\
\hline \multicolumn{5}{|c|}{ Чернозем обыкновенный пахотный: } \\
\hline гумус & 4,13 & 0,27 & 0,12 & 6,6 \\
Сорг & 2,39 & 0,16 & 0,07 & 6,6 \\
$\mathrm{~N}$ & 0,31 & 0,03 & 0,01 & 10,1 \\
\hline
\end{tabular}

Примечание. М - среднее арифметическое значение, S - стандартное отклонение, $\mathrm{m}$ - ошибка стандартного отклонения, V - коэффициент вариации.

Выявлены некоторые особенности современной агрогенной трансформации почвенного органического вещества Северного Казахстана на основании результатов исследований содержания Сорг и N в верхнем слое (в основном 0-25 см) черноземов в условиях длительных полевых опытов за последние 25 лет. Установлено, что в настоящее время в результате воздействия различных способов обработки чернозе- мов южных замедляются темпы снижения содержания гумуса по сравнению с таковыми предшествующего периода их сельскохозяйственного использования, но практически они, в т.ч. и плоскорезные обработки, не приостанавливают процесс дегумусирования. Содержание гумуса в почвах на вариантах с бессменной яровой пшеницей уже близко таковому на бессменном чистом пару. Имеются достаточные основания предполагать, что причиной дегумусирования черноземов южных могут выступать как биохимические (минерализация), так и физические (дефляция) потери гумуса. Особую опасность представляет ветровая эрозия, в результате которой гумус может снижаться ниже минимального его содержания, т.е. за счет убыли трудновосполнимой инертной части [13].

Таблица 3 - Оценка достоверности различий по содержанию гумуса, $\mathrm{C}_{\text {орг }}$ и азота в черноземах различных вариантов полевого опыта

\begin{tabular}{|c|c|c|c|}
\hline \multirow[b]{2}{*}{$\begin{array}{c}\text { Пока- } \\
\text { затель, } \\
\text { t- } \\
\text { крите- } \\
\text { рий }\end{array}$} & \multicolumn{3}{|c|}{ Варианты сравнения } \\
\hline & $\begin{array}{c}\text { Чернозем } \\
\text { обыкно- } \\
\text { венный - } \\
\text { Чернозем } \\
\text { южный } \\
\text { карбо- } \\
\text { натный }\end{array}$ & $\begin{array}{l}\text { Зернопаровой } \\
\text { севооборот, } \\
\text { N30Р20- } \\
\text { Зернопаровой } \\
\text { севооборот, } \\
\text { без удобре- } \\
\text { ний (черно- } \\
\text { зем южный } \\
\text { карбонатный) }\end{array}$ & $\begin{array}{c}\text { Зернопаровой } \\
\text { севооборот, без } \\
\text { удобрений - } \\
\text { Бессменная } \\
\text { яровая пшеница } \\
\text { без удобрений } \\
\text { (чернозем юж- } \\
\text { ный карбонат- } \\
\text { ный) }\end{array}$ \\
\hline $\begin{array}{l}\text { Гумус, } \\
\text { tфакт }\end{array}$ & $4,27 * *$ & $2,77^{*}$ & 2,67 \\
\hline $\begin{array}{l}\text { Сорг, } \\
\text { tфакт }\end{array}$ & $4,24 * *$ & $2,68^{*}$ & 2,68 \\
\hline $\begin{array}{l}\mathrm{N}, \\
\text { tфакт }\end{array}$ & $4,16^{* *}$ & 0,95 & 0,89 \\
\hline
\end{tabular}

Примечание. Различия значимы при уровнях вероятности $\mathrm{P}=0,90$ * и $\mathrm{P}=0,95 * *$.

На восстановление запасов инертной части гумуса в верхнем слое черноземов на основании данных радиоуглеродного датирования по самым приблизительным оценкам потребуется не менее 1,0-1,5 тысячи лет $[14 ; 15]$.

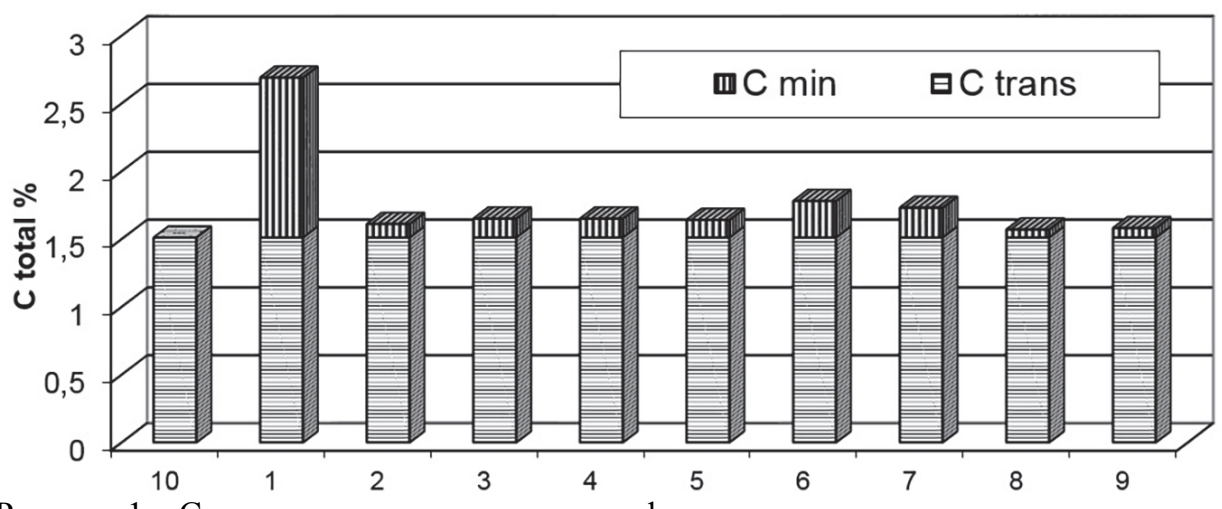

Рисунок 1 - Содержание инертного и трансформируемого органического углерода.

Примечание. Обозначения вариантов опыта те же, что и в табл. 1

На пахотных обыкновенных черноземах в последний период их агрогенного использования предположительно потерь гумуса не наблюдается. Вероятно, это связано с тем, что изучаемые полевые участки
Карабалыкской опытной станции защищены лесополосами, препятствующими ветровой эрозии, в отличие от таковых Казахского НИИ зернового хозяйства им. Бараева. 
Куришбаев А.К., Звягин Г.А., Ярославцева Н.В., Когут Б.М.

Требуется проведение дальнейших экспериментальных исследований органического вещества пахотных черноземов Северного Казахстана для подтверждения высказанных положений о направленности процессов гумусообразования. Кроме того, необходима закладка делянок бессменного чистого пара в условиях длительных полевых опытов Казахстана.

\section{СПИСОК ЛИТЕРАТУРЫ:}

1. Тюрин И.В. Органическое вещество почв. Л.: Сельхозгиз, 1937. 288 с.

2. Кононова М.М. Проблема почвенного гумуса и современные задачи его изучения. М.: Изд-во АН CCСР, 1951. $390 \mathrm{c}$.

3. Чесняк Г.Я., Гаврилюк Ф.Я., Крупеников И.А., Лактионов Н.И., Шилихина И.И. Гумусовое состояние черноземов // Русский чернозем. 100 лет после Докучаева, ч. 2, гл. 4. М.: Наука, 1983. С. 186-198.

4. Ярославцева Н.В. Гумусовое состояние черноземов южных карбонатных Северного Казахстана: дис. ... канд. биол. наук. Алма-Ата, 1990. 145 с.

5. Аринушкина Е.В. Руководство по химическому анализу почв. М.: МГУ, 1977. 489 с.

6. Доспехов Б.А. Методика полевого опыта. М.: Агропромиздат, 1985. $351 \mathrm{c}$.

7. Классификация и диагностика почв СССР. Почвенный ин-т им. В.В. Докучаева. М.: Колос, 1977. 224 с.

8. Гришина Л.А., Орлов Д.С. Система показателей гумусного состояния почв // Проблемы почвоведения. М.: Наука, 1978. С. 43-47.
9. Кёршенс М. Значение содержания гумуса для плодородия почв и круговорота азота. Посвящается 100-летию со дня рождения профессора, академика И.В. Тюрина // Почвоведение. 1992. № 10. С. 122-131.

10. Когут Б.М. Оценка содержания гумуса в пахотных почвах России // Почвоведение. 2012. № 9. C. 944-952.

11. Масютенко Н.П., Когут Б.М., Татошин И.Ф. Закономерности влияния обработок почвы на содержание, состав и природу гумусовых веществ черноземов // Прогноз развития эрозионных процессов и устойчивость агроландшафтов к воздействию естественных и антропогенных факторов. Курск, 1990. С. 86-103.

12. Когут Б.М., Травникова Л.С., Титова Н.А., Куваева Ю.В., Ярославцева Н.В. Влияние длительного применения удобрений на содержание органического вещества в легких и илистых фракциях черноземов // Агрохимия. 1998. № 5. С. 13-20.

13. Когут Б.М. Оценка уровней эродированности черноземов по относительной степени их гумусированности // Бюллетень Почвенного ин-та им. В.В. Докучаева. 2015. № 78. С. 59-69.

14. Герасимов И.П., Чичагова О.А. Некоторые вопросы радиоуглеродного датирования почвенного гумуса // Почвоведение. 1971. № 10. С. 3-11.

15. Чичагова О.А., Черкинский А.Е. Проблема радиоуглеродного датирования почв // Почвоведение. 1985. № 11. С. 63-75.

\section{KAZAKHSTAN BLACK SOIL ORGANIC SUBSTANCE AGROGENIC TRANSFORMATION} (C) 2016

A.K. Kurishbayev, doctor of agricultural sciences, professor, chairman of the board G.A. Zvyagin, doctoral candidate of the Chair of Soil Science and Agricultural Chemistry S. Seifullin Kazakh Agro-Technical University, Astana (Kazakhstan)

N.V. Yaroslavtseva, candidate of agricultural sciences, researcher of the Department of Soil Biology and Biochemistry

B.M. Kogut, doctor of agricultural sciences, head of the Department of Soil Biology and Biochemistry V.V. Dokuchaev Soil Science Institute, Moscow (Russia)

Abstract. Currently despite the extended study of the temporary dynamic of the cultivated soil organic substance on the global scale scientists pay much attention to the establishing the patterns of its quantitative transformation on the regional level depending on the systems of agricultural exploitation for the purpose of clarifying the worldwide estimate of humus reserve in relation to the issue of the «greenhouse effect». In this regard we have examined the modern dynamic (1990-2015) of the regular and southern black soil organic substance in the conditions of long-term stationary field experiments in the primary grain-sowing region of the Northern Kazakhstan. Based on the data from alternative time periods on the proportion of Соргаnd $\mathrm{N}$ in the upper (mainly 0-25 $\mathrm{cm}$ ) layer of virgin and agrogenic black soil of Akmolinsk and Kostanay regions of Kazakhstan we have discovered the distinctive characteristics of changes in the content of soil organic substance. It has been demonstrated that the content of humus in the regular black soil is significantly higher than that in the southern carbonated black soil. Evaluation of transforming and inert pool of organic carbon in virgin and agrogenic variants of southern black soil has been made. It has been established that currently in the result of influence from various methods of southern black soil treatment the rate of humus percentage decrease is slowing down in comparison with that of the previous period of its agricultural exploitation, however, in practice, those methods, including the subsurface tilling, do not halt the de-humusization process. Content of humus in soil of the variants with continuous spring wheat is approaching that with continuous complete fallow. There are sufficient grounds to suggest that the reason for de-humusization of the southern black soil could reside in biochemical (mineralization), as well as physical (deflation) loss of humus. Particular danger comes from the wind erosion resulting in percentage of humus dropping even below its minimal value, i.e. due to the decrease of nearly unrecoverable inert part. In agrogenic regular black soil, during the closing period of its agricultural exploitation, there has been no humus loss detected, which is most probably related to the existence of protective anti-erosion forest belts in the studied fields area.

Keywords: organic substance; regular black soil; southern black soil; agrogenic soil; low-humus soil; grain-fallow crop rotation; continuous wheat; subsurface tilling; zero technology; de-humusization; inert humus; Nortehrn Kazakhstan; Akmolinsk region; Kostanay Region. 